\title{
Assessment of a portfolio as an effective tool to promote self-management among patients with ischemic heart diseases: A preliminary trial
}

\author{
Haruka Otsu ${ }^{1}$, Michiko Moriyama², Yuasa Yuka ${ }^{3}$, Toyonori Omori ${ }^{4}$ \\ ${ }^{1}$ Graduate School of Health Sciences, Hirosaki University, Hirosaki, Japan; h_otsu@cc.hirosaki-u.ac.jp \\ ${ }^{2}$ Division of Nursing Science, Institute of Biomedical \& Health Sciences, Hiroshima University, Hiroshima, Japan; \\ morimich@hiroshima-u.ac.jp \\ ${ }^{3}$ Hiroshima University Hospital, Hiroshima, Japan; riyuasa@hiroshima-u.ac.jp \\ ${ }^{4}$ National Institute of Health and Nutrition, Shinjuku, Japan; green_omori@yahoo.co.jp
}

Received 7 January 2014; revised 4 February 2014; accepted 11 February 2014

Copyright (c) 2014 Haruka Otsu et al. This is an open access article distributed under the Creative Commons Attribution License, which permits unrestricted use, distribution, and reproduction in any medium, provided the original work is properly cited. In accordance of the Creative Commons Attribution License all Copyrights @ 2014 are reserved for SCIRP and the owner of the intellectual property Haruka Otsu et al. All Copyright (C) 2014 are guarded by law and by SCIRP as a guardian.

\section{ABSTRACT}

Portfolio has been used as an approach to promoting self-learning in the field of education and its effectiveness was reported in school education. The purpose of this study was to assess effectiveness of portfolio as a tool for educating patients with ischemic heart diseases as selfmanagement behavior in terms of applicability and efficacy. Subjects of this study were seventeen patients who had myocardial infarction or angina. They were assigned to collect information about their themes chosen from diet, exercise, alcohol intake, smoking cessation, and stress management and gathered in files. Thirty minutes face-to-face educational interviews were conducted by a nurse for once per month over three months. Self-management, self-efficacy, and physiological data were evaluated for baseline and 3 months. Two participants dropped within two months (completion rate is $\mathbf{8 8 . 2} \%$ ). The results showed that portfolio was effective as a self-management education tool on patients who were willing to participate, but did not improve physiological data if they did not continuously implement lifestyle change. Moreover it was dangerous when the patients acquired incorrect information on diseases. For these patients, health education by health professionals is required prior to conducting portfolio. Attributes fit for portfolio were assessed. Effectiveness of portfolio related to high self-efficacy and high self-management, but did not relate to living status, having job, educational background, and health locus of control.

\section{KEYWORDS}

Portfolio; Ischemic Heart Diseases; Self-Learning; Self-Management; Self-Efficacy

\section{INTRODUCTION}

Patient education is a key to prevent recurrences and exacerbation of myocardial infarction. The purpose of the secondary prevention is to enhance recognition of disease condition, provide knowledge and skills for lifestyle modification, and emphasize the importance of proper and continuous medical intervention [1]. With the goal of achieving behavior modification, patient education based on principles of adult learning (learning from experience) has proved more effective than informative learning administered in a didactic manner by healthcare professionals [2,3].

A number of cognitive behavioral theories also show high quality evidence of developing self-efficacy through a method consisting of small steps in goal-setting type education [4,5]. Group guidance using group dynamics through peer support, individualized education utilizing cardiac rehabilitation, distant education through internet and telephone, self-monitoring using a journal kept by the patient, methodology using visual materials such as DVDs, as well as traditional face-to-face interviews are reported as methods of patient education [2,6]. However, a little payment is made for patient education under the Japanese health insurance system, therefore most patient 
education is provided in just one session of no more than one hour using booklets that are available nationwide [7].

Booklets, brochures, and DVDs are easy-to-use approaches in the comparative efficacy of patient education, but patients tend to become passive and it is more difficult to modify their behavior than to be educated through face-to-face education, counseling, and support groups [6]. Booklets and brochures, on the other hand, also have disadvantages because it is difficult to correct wrong understandings among patients and to teach them to adjust to individual situations [8]. Individual face-to-face education is the most effective approach in order to obtain efficacy of implementation when ease of use is not considered [6].

Portfolio has been used as an approach to promoting self-learning in the field of education $[9,10]$ and its effectiveness was also reported in postgraduate and undergraduate education for nursing and medical professionals [11]. If this education method is useful for fostering selflearning, it might be applicable to the education on patients who need to acquire self-management skills. We, therefore, consider the portfolio as a tool for educating patients with ischemic cardiac disease with the aim of lifestyle modification. There are some studies on portfolio which were applied to patient education, but these were for patients with schizophrenia and type 2 diabetes. In these studies, portfolio was reported to be effective; however, participants were limited to only one to three cases [12-14]. Hence, we investigate effectiveness of the portfolio as a tool for educating patients with ischemic heart diseases to promote self-management behavior in terms of applicability and efficacy.

\subsection{Operational Definition of the Term}

Portfolio: Portfolio is one methodology for promoting self-learning in patients. Patients can review their progress and the efforts which they have made in learning information by using the portfolio, and an instructor (a nurse) evaluates the information in the portfolio. Basically, this is a process of developing patient perception and giving support to properly acquired self-management behavior.

\subsection{Framework of the Concept in This Study}

The framework of the concept in this study is shown in Figure 1.
1) Process of modifying patients' behavior by using portfolio

Kolb [15], who developed a theory of experiential learning, stated that learning in adulthood has a learning cycle with 4 different stages: 1) doing or initiating related to a new experience (concrete experience), 2) skills of observation and reflection through the perspective of the new experience (reflective observation), 3) analytical ability based on reflective observation to produce an integrated concept (abstract conceptualization) and 4) skills in decision-making which permit the use of this new concept for implementation and problem solution (active experimentation). We added a plan for implementation to the cycle of learning and intervention from a nurse to promote this cycle. Figure 1 demonstrates the process of how learning effects appear among patients in this learning cycle.

In particular, patient attitude towards assignments is affected by circumstances such as ease of access to source material and specific experiences. During portfolio implementation, they are proactive in collecting the necessary information through a system of trial and error, and reflect on their usual behavior in comparison with those in collected information from a variety of angles (reflective observation). Moreover, they consider future desirable behavior (abstract conceptualization), plan strategies for implementation (implementation of the plan), and carry out these strategies (active experimentation). Finally, new modified behavior becomes meaningful through evaluation by a nurse. Thus, it is considered that the portfolio implementation contributes to adult learning through this process.

\section{2) Portfolio effects: setting evaluation indicators}

Self-efficacy will be achieved in the beginning if adult learning is promoted. After that, self-management behavior will be achieved as a result and finally physiological data will improve.

\section{METHOD}

\subsection{Participants}

Inclusion criteria: Participants were patients diagnosed with myocardial infarction or angina pectoris in the past 6 months, who made regular (once per month) hospital visits in a general hospital and agreed to participate in this study.

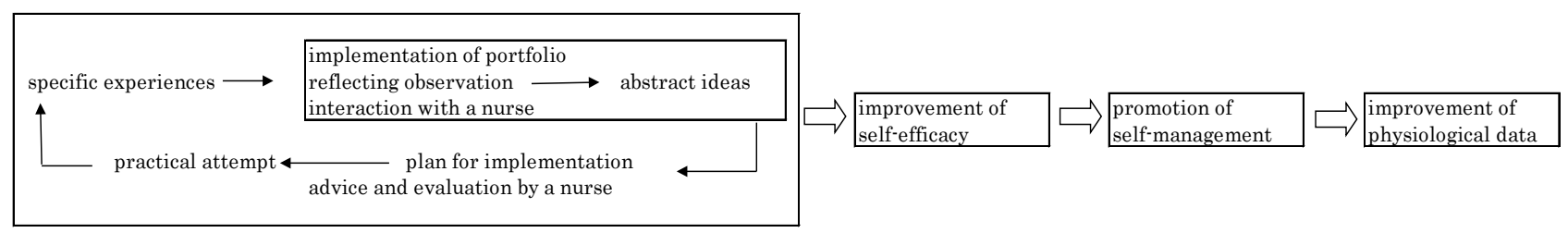

Figure 1. A framework of the concept in this study. 
Exclusion criteria: Patients who have cognitively impaired or physical difficulties for portfolio implementation, and who have serious diseases such as cancer or brain disease and mental disabilities were excluded.

We asked a physician to introduce patients who filled the criteria, and we informed gist of this study to the patients and obtained their consent.

\subsection{Period of the Study}

Enrollment of participants was conducted from June 1 to 30,2010 . Intervention was carried out from July 1 to October 31, 2010.

\subsection{Study Design}

A pre-post comparison design within the intervention group was used as applicability on participants who was being examined for the first time.

\subsection{Procedures}

The procedures for this study are shown in Figure 2. 1) At the first interview, participants received files, sticky notes, and a pen. A nurse explained the purpose of this portfolio, implementation methods, and enhancement details. 2) Participants selected one theme in which they were interested from diet, exercise, reduction of alcoholintake, smoking cessation, and stress management on selfmanagement of myocardial infarction and angina pectoris, and they collected information about these themes and kept it in their files. Furthermore, if they noticed anything in particular, they were required to write it on a sticky note. 3) Face-to-face interviews were conducted one, two and three months after intervention commenced. These were conducted by a nurse in a private room for 30 minutes during hospital visits. First, participants showed the collected information to the nurse and explained what they learned. Next, the nurse evaluated it and praised the patient, with asking them where they collected the information and what they had noted in comparison with their lifestyle habit. After the patient and the nurse discussed this, the nurse asked about implementation of self-management, reasons for non-implementation, results, improvements, and what participants had noticed and learned after 2 months. If the patients had insufficient knowledge, the nurse corrected this and provided them with accurate information. In addition, the nurse asked about data collection sources and gave advice about finding them.

Meanwhile, we set the intervention period as three months because participants with myocardial infarction were assumed to be able to continue self-management if they keep high self-efficacy for 3 months after discharge from a hospital. Behavioral modification also occurred immediately after receiving instruction and significant difference was observed after 3 months [16].

\subsection{Evaluation Indicators and Evaluation Points}

Self-management and self-efficacy were evaluated as primary endpoints, and physiological data were evaluated as secondary endpoints.

1) A questionnaire to evaluate the self-management behavior of patients with ischemic heart disease [17] (hereinafter referred to as "scale of self-management behavior")

This is a specialized scale for evaluating self-management behavior in ischemic heart disease, which consists of 32 items with answers ranging from "never (1 point)" to "always (4 points)". High scores are indicated as excellent self-management behavior.

2) The scale of self-efficacy on health behavior in Chronic Disease Patients [18]

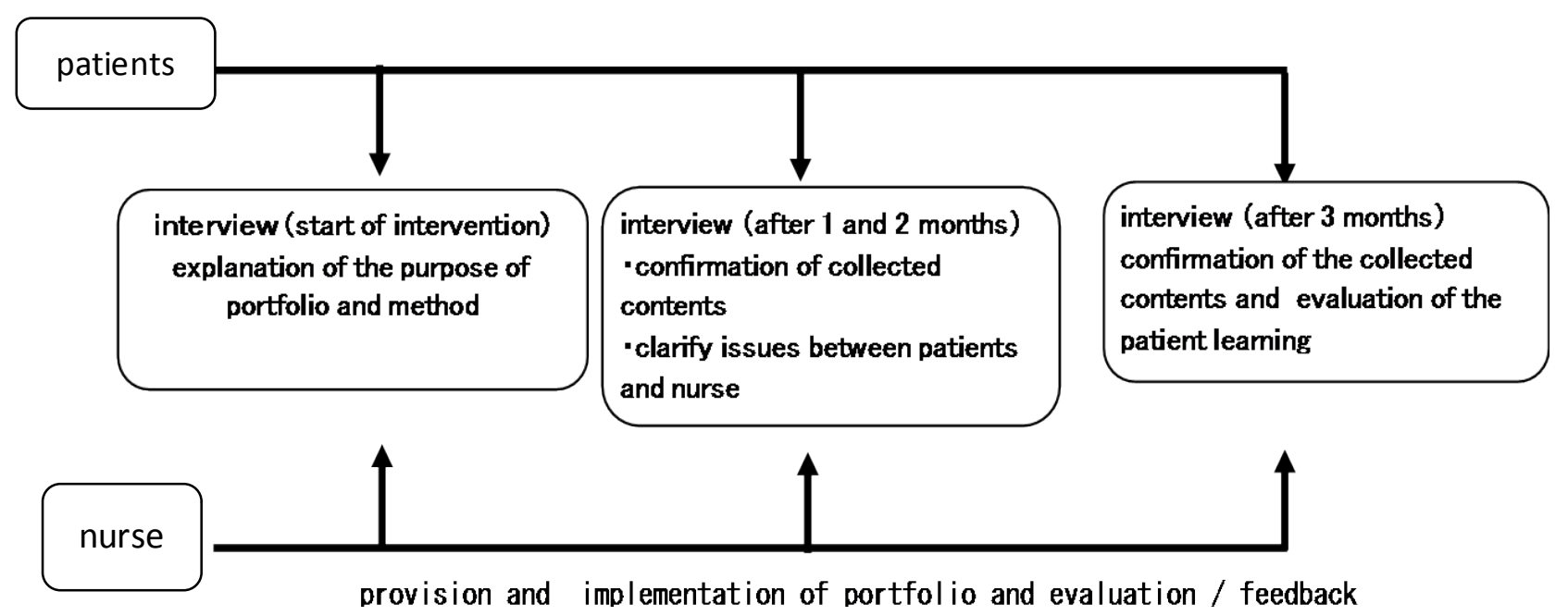

Figure 2. A portfolio method in this study. 
This scale consists of 25 items and has two sub-concepts, which are positivity of copying behavior with respect to the disease, and feelings of control with respect to health. Answers are ranging from "not applied at all (1 point)" to "well applied (4 points)" by degree of performance. The highest score is 96 , and a high score indicates high self-efficacy.

3) Physiological data

Weight, body-mass index (BMI), abdominal circumference, blood pressure (systolic and diastolic pressure), HDL-cholesterol, LDL-cholesterol, and triglycerides (TG) were collected.

4) Descriptive evaluation of portfolio implementation

This includes whether the portfolio had been implemented, the process of behavior modification, and evaluation after implementation. It also includes whether information was collected and the contents of it were descriptively evaluated.

Scales of self-management and self-efficacy were administered to the participants, and physiological data were collected from their medical records before the first intervention and immediately after it (3 months). Weight, abdominal circumference, and blood pressure were measured by the nurse at each interview.

\subsection{Attributes Affecting Portfolio Implementation}

Demographic profiles, such as age, sex, marital and living status, occupation, academic background as a basic attribute, diagnosis, experience of lifestyle education by medical professionals, and lifestyle habits of alcohol-intake and smoking were evaluated at the beginning of intervention. Locus of control was evaluated with the following scales.

\subsection{Japanese Version of the Health Locus of Control Scale [19] (JHLC)}

This scale measures causal attribution with respect to health and disease (locus of control) on the basis of individual belief systems. This scale modified the original health locus of control scale [20] to fit Japanese belief system. The factors in health and disease tend to be attributed to the following 5 factors: Internal (oneself), Family, Professional (medical professionals), Chance (accident), Supernatural (key player beyond oneself such as Shinto and Buddhist deities and spirits). Each subscale is evaluated and a high score indicates a strong tendency.

\subsection{Data Analysis}

The contents of portfolio implementation by participants were described in the learning process from the viewpoints of changes in cognition and behavior. Be- cause based on the nurse's report, we found two types of participants: voluntary participate and involuntary participate, we divided the participants into two groups and compare with them. Participants who felt reluctant to collect information and/or quit portfolio activity were placed as involuntary group; whereas participants who felt interesting in collecting information and voluntarily involved in portfolio activity were placed as voluntary group.

Chi-square test was conducted on baseline comparison of participants' attributes. Analysis of Variance (ANOVA) was used on baseline comparison of scales and physiological data. Repeated measure of two-way ANOVA and analysis of covariance (ANOCVA), when baseline comparison had significant differences, were applied for evaluating chronological changes of all indicators. To examine influence of gender during implementation, chisquare test was utilized between both sexes. To evaluate change in abdominal circumference between the two groups and time, repeated measure of two-way ANOVA was conducted.

\subsection{Ethical Attention}

The study was carried out with the approval of ethical committees of a hospital. Participants agreed to participate in this study after receiving an explanation and signed in the consent form.

\section{RESULTS}

\subsection{Completion Rate of This Study}

Seventeen outpatients agreed and were referred to this study; however, two dropped out; one (male, age 53, living with a family, having a spouse, works as a carpenter, drinks beer 1.5 L/day, smoke 1 pack of cigarette/day) dropped out within one month due to time constraints; the other (male, age 50, living with a family, having a spouse, a company employee, stopped drinking and smoking after the attack) dropped out after two months due to a health problem. Finally, 15 completed three times interviews and were analyzed (completion rate is $88.2 \%$ ).

\subsection{Participants' Situation Concerning Basic Attributes}

Average age was $60.1 \pm 11.7$ (range from 33 to 79 ; in 30 's 1 , in 40 's 1 , in 50 's 3 , in 60's 7 , in 70's 3 ). There were 11 male (73.3\%) and four female (26.7\%); four lived alone (26.7\%) and 11 lived with their families. Ten had jobs (66.7\%), of which three were female and seven were male. Two graduated from junior high school, eight from high school (53.3\%), and three from university. Seven (46.7\%) had experienced lifestyle education such as diet, exercise, and smoking cessation from medical 
professionals. Two (13.3\%) smoked and four took alcohol (26.6\%). Seven were diagnosed as acute myocardiac infarction, and eight as angina pectoris.

\subsection{Evaluation of Portfolio Implementation}

\section{Participant implementation status}

Fourteen participants (93.3\%) collected information in the portfolio in the 1st month, 11 (73.3\%) in the 2nd month, and eight (53.3\%) in the 3rd month. Six (40.0\%) implemented the portfolio in the 1st month, nine (60.0\%) in the 2nd month, and six (40.0\%) in the 3rd month. The contents of collected information by participants included ischemic cardiac disease explanation such as "myocardial infarction and other diseases", "the most recent medical therapy for myocardial infarctions", "low sodium diet and hypercholesterolemic diets", and "main points of exercise”. During three month, eleven participants (73.3\%) collected information more than once, six (40.0\%) more than twice, and four (26.7\%) more than three times.

Participants who implemented the portfolio involuntarily (Table 1)

Nine out of 15 participants (60\%) implemented the portfolio involuntarily because they could not find information by themselves, and stopped collecting information or showed negative behavior, and could not change their behavior. Five of them self-reported that they did not have any experience of having education from medical professionals. Their information sources were mainly newspapers, but one participant collected information other than newspapers when he could not find any information in newspapers. Only one participant used the internet.

Newspapers mainly provided information about disease explanation and its medical therapy, as a result, participants gave up the assignment because they could not find any useful information for them. They implemented general advice from colleagues, friends, and families. This information, however, included misleading information, and as a result, they implemented the wrong health behavior.

As summary, participants could not obtain necessary information, even though they read an article, and felt that the information in newspapers was not suited to them. Therefore, they gave up collecting information and carried out the general advice of their colleague regardless of whether it was suited for their health or not. Some of them asked for support from their families, but they could not find out accurate information.

Participants who implemented the portfolio voluntarily (Table 2)

Six participants implemented the assignment voluntarily, and their lifestyle habits changed effectively after three months interventions. Four out of six participants did not have any experience of being educated at healthcare facilities regardless of their educational level.

They did not show emotional difficulties in collecting information and enjoyed doing it from the beginning. They took pleasure in obtaining new information and

Table 1. Participants' behavior in those who implemented the portfolio involuntarily.

\begin{tabular}{|c|c|}
\hline Resource of Portfolio & $\mathrm{n}=9$ \\
\hline Only newspapers & 6 \\
\hline Only newspapers, but could not search by themselves, asked family for help (family helped to cut out newspaper articles) & 2 \\
\hline Only newspapers, due to no information found, then asked friends/colleagues & 2 \\
\hline Only newspapers, due to no information found, then asked a doctor/nurse & 1 \\
\hline Due to no information found in newspapers, read magazines & 1 \\
\hline \multicolumn{2}{|l|}{ Response to information } \\
\hline Articles were all about disease and medical treatment. not relevant to them (confused, difficult) & 8 \\
\hline Articles described patients’ experiences (story) were useful & 3 \\
\hline Newspaper articles did not fit their condition/situation (confused) & 1 \\
\hline Colleagues gave advice (most of them were misleading and incorrect) & 1 \\
\hline Doctors did not give examples suitable to his lifestyle & 1 \\
\hline Quit searching because of stress & 1 \\
\hline \multicolumn{2}{|l|}{ Action taken (final results) } \\
\hline No information possible to implement, so followed general advice by others (mostly incorrect) & 5 \\
\hline Quit portfolio. Listened the nurse’s advice, but did not implemented & 5 \\
\hline Quit portfolio, gave up everything “nothing helpful” & 2 \\
\hline Continued to search for articles, but could not find nor implement & 1 \\
\hline Serched articles, boasted to his colleagues what he found, but did not appliy to him & 1 \\
\hline
\end{tabular}


Table 2. Brief overview of changes in patients who implemented the portfolio voluntarily.

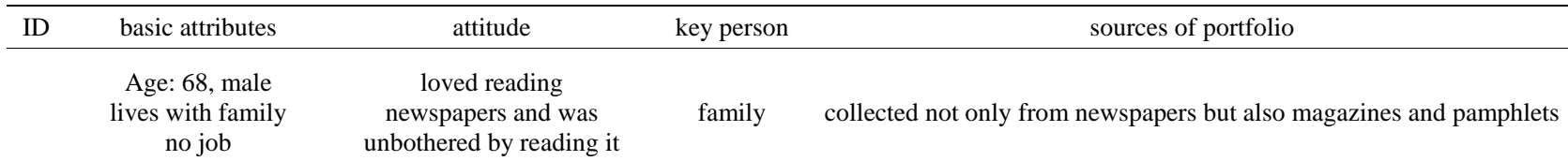

Change process

Collected articles on the disease and implemented diet and exercise. Based on the nurse's advise, corrected misunderstandings. Continued to do diet and exercise properly. His collection grew larger to include articles about stress.

Evaluation of portfolio His work benefited him and felt satisfaction. Cut back on eating mayonnaise and eggs. Lost weight and kept improving.

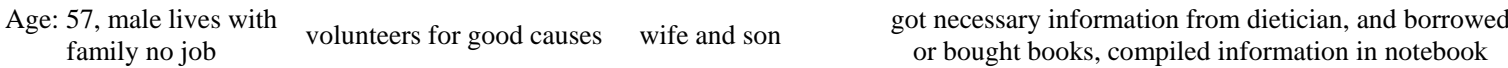

2 Collected information on the theme of diet and implemeted it. The nurse was impressed with his behavior and encouraged him to continue, telling him the proper amounts and criteria to combat his self-imposed strict constraints. His consciousness changed as well.

Got to know about cholesterol-rich food. His family also changed. Changed to a low-sodium diet and felt that food was salty when he ate out. Felt good and his stress decreased. Understood himself well because he obtained new knowledge and hoped to continue like this.

\begin{tabular}{ccc}
\hline Age:33, male & takes things easy & \\
$\begin{array}{c}\text { lives with his family } \\
\text { business position }\end{array}$ & $\begin{array}{c}\text { usually reads newspaper, } \\
\text { when finds something } \\
\text { relevant, clips it }\end{array}$ & no
\end{tabular}

Clipped newspaper articles as always when caught his attention. The nurse advised him to use the information step by step taking a look at his lifestyle. When he faild to collect any new information, the nurse encouraged him with advice. Found importance in having peers.

Acquired sufficient knowledge, though his knowledge was unclear before. Accepted his disease as it was and took resonsibility for prevention.

$\begin{array}{ccc}\begin{array}{c}\text { Age:70, female lives } \\ \text { alone sales position }\end{array} & \begin{array}{c}\text { wants to live with her } \\ \text { sister with good health }\end{array} & \text { sister } \\ \text { or medical therapy and also read newspapers }\end{array}$

Found that she did not know about her disease at all, so started to think about getting an understanding of her disease. Tentatively started diet, exercise, and self-monitoring. The nurse approved her behavior change and advised her to continue them. The nurse connected the things that

4 this patient realised in daily life to the contents of a textbook. The nurse advised her to keep working hard and to take time and not get upset if her weight plateaued. Started to watch out for various things and continued to improve. Reviewed her implementation in the context of the outcome of her lab data.

Felt the need to learn and got into reading various things daily things. Her consciousness changed and she realised that her implementation lead to good results. Her lifestyle habits changed such as diet, low-stress, more regular lifestyle, and she continued to measure her weight.

Age:66, male lives with $\quad$ always love to look $\quad$ wife $\quad$ read newspaper and internet, searched

family no job for new information wife website if did not understand newspaper articles

First researched on wrong information, then gradually reached to right information by the nurse's advoice. The nurse approved his collection

5 and advised him to focus on topics. Reviewed his dietary life and told his wife where wanted to make changes. The nurse approved his approach and advised him to continue.

The portfolio was beneficial. Intensive learning during this time was useful because could reconsider his daily habits and could also pass on what he learned to his wife.

$\begin{gathered}\text { Age:61, female } \\ \text { lives alone } \\ \text { restaurant business }\end{gathered}$ wants to review her lifestyle nobody $\quad \begin{gathered}\text { no information in newspapers, went to bookstores, but could not get } \\ \text { good information, then hospital leaflets advised by the nurse }\end{gathered}$

Researched in newspapers but no helpful information. But wanted to go forwarded, the nurse advised her to use the leaflets available at the

6 hospital as a reference. Read a booklet at a hospital and found the necessary information. After that, she became more aware of her lifestyle habits.

Started by doing whatever she could and ate a lot of vegetables, reduced sodium and weight, and started paying attention to meals overall. Bought a blood pressure machine and started measuring it. Started walking. Made sure to research unclear points until understood them. As a result, her aches and pains disappeared and wants to continue with the portfolio.

knowledge. They researched newspaper articles, went to libraries, researched on the internet, and then found out information from health professionals. They mainly collected information about the disease in the first month and then gradually focused on specific themes according to the nurse's advice and then they were about to collect the necessary information. They particularly looked back on their lifestyle habits and after that set specific goals 
and incorporated them into their lifestyle.

\subsection{Attributes Affecting the Portfolio Implimentation}

The attributes that were compared between voluntary and involuntary participants with respect to portfolio implementation are shown in Table 3. Any attribute did not specifically contribute to voluntary activity. Age, living arrangement, and having job did not affect; however, more people with a spouse were in involuntary group, and more people with financially satisfied and higher educational background were in the voluntary group.

Self-management and self-efficacy were higher in the voluntary group, but it was no statistically significant. No differences in health locus of control, internal and external (chance, supernatural) were found. The ratio of portfolio implementation of collecting information over three months was significantly higher in females than in males $(p=0.033)$ (Table 4).

\subsection{Changes in Primary Endpoints}

Self-management and self-efficacy in the voluntary group were higher than those in the involuntary group in the baseline, and the scores improved in the voluntary group as we expected after three months of intervention. Improvement of self-management scores was statistically significant within the group $(p=0.004)$ (Table 5).

\subsection{Changes in Secondary Endpoints}

The baseline comparison of physiological data was shown in Table 3, and the chronological changes were shown in Table 5. The results showed no significant changes in any indicators. As shown in Table 6, the group of continuous implementation of contents collected in the portfolio for 3 months was significantly improved in comparison with the group of continuous implementation of contents collected in the portfolio for less than 2 months $(p=0.036)$.

\section{DISCUSSION}

\subsection{Applicability of Portfolio as a Tool for Patient Education for Patients with Ischemic Heart Disease}

All participants consented by themselves; however, nine implemented the portfolio involuntarily. Moreover, they could not collect proper information and as a result they had incorrect information or could not judge which

Table 3. Baseline comparison between the groups.

\begin{tabular}{|c|c|c|c|c|}
\hline & voluntary group $n=6$ & involuntary group $n=9$ & p-value & \\
\hline sex (male) & $4(66.7 \%)$ & $7(77.8 \%)$ & 1.000 & $\mathrm{a}$ \\
\hline age (years old) & $60.7 \pm 11.0$ & $59.2 \pm 13.7$ & 0.817 & $\mathrm{~b}$ \\
\hline living alone & $2(33.3 \%)$ & $2(22.2 \%)$ & 1.000 & a \\
\hline person with a job & $4(66.7 \%)$ & $6(66.7 \%)$ & 1.000 & a \\
\hline elderly person (age 65 over) & $3(50.0 \%)$ & $3(33.3 \%)$ & 0.622 & a \\
\hline high school graduate (or higher) & $5(83.3 \%)$ & $7(77.8 \%)$ & 1.000 & a \\
\hline financial situation (satisfied) & $5(83.3 \%)$ & $5(55.6 \%)$ & 0.580 & a \\
\hline self-management (score) & $103.8 \pm 13.5$ & $100.6 \pm 11.5$ & 0.622 & $\mathrm{~b}$ \\
\hline self-efficacy (score) & $81.5 \pm 12.7$ & $77.9 \pm 9.6$ & 0.541 & $\mathrm{~b}$ \\
\hline \multicolumn{5}{|l|}{ HLC (score) } \\
\hline Internal & $22.3 \pm 4.2$ & $21.8 \pm 3.9$ & 0.798 & $\mathrm{~b}$ \\
\hline Professional & $19.2 \pm 5.6$ & $20.4 \pm 3.7$ & 0.600 & $\mathrm{~b}$ \\
\hline Chance & $15.2 \pm 5.6$ & $16.7 \pm 6.9$ & 0.665 & $\mathrm{~b}$ \\
\hline Supernatural & $13.3 \pm 3.3$ & $13.9 \pm 3.4$ & 0.760 & $\mathrm{~b}$ \\
\hline weight (kg) & $66.4 \pm 5.7$ & $68.7 \pm 15.8$ & 0.748 & $\mathrm{~b}$ \\
\hline BMI & $24.6 \pm 2.2$ & $24.5 \pm 3.9$ & 0.961 & $\mathrm{~b}$ \\
\hline abdominal circumference $(\mathrm{cm})$ & $91.1 \pm 6.7$ & $90.5 \pm 9.0$ & 0.894 & $\mathrm{~b}$ \\
\hline systolic blood pressure (mmHg) & $119.7 \pm 14.2$ & $138.7 \pm 17.6$ & $0.046^{*}$ & $\mathrm{~b}$ \\
\hline diastolic blood pressure (mmHg) & $71.7 \pm 7.1$ & $77.1 \pm 13.6$ & 0.386 & b \\
\hline HDL (mg/dl) & $44.7 \pm 8.2$ & $50.9 \pm 11.4$ & 0.211 & $\mathrm{~b}$ \\
\hline LDL (mg/dl) & $93.2 \pm 26.9$ & $98.4 \pm 19.6$ & 0.637 & $\mathrm{~b}$ \\
\hline TG (mg/dl) & $123.3 \pm 29.2$ & $133.6 \pm 49.0$ & 0.672 & $\mathrm{~b}$ \\
\hline
\end{tabular}

${ }^{\mathrm{a}}$ Chi-square test, ${ }^{\mathrm{b}}$ ANOVA. Upper: baseline attributes, Lower: physiological data ${ }^{*} p<0.05$. 
Table 4. Duration of contents implementation of participant by gender $(\mathrm{n}=15)$.

\begin{tabular}{rccc}
\hline & male & female & $p$-value \\
\hline implementation more than 1 month & $8(72.7 \%)$ & $3(75.0 \%)$ & 0.635 \\
implementation more than 2 months & $3(27.3 \%)$ & $3(75.0 \%)$ & 0.235 \\
implementation more than 3 months & $1(9.1 \%)$ & $3(75.0 \%)$ & $0.033^{*}$ \\
\hline${ }^{*} p<0.05$. & &
\end{tabular}

Table 5. Chronological changes of the groups $(n=15)$.

\begin{tabular}{|c|c|c|c|c|c|c|c|c|c|c|c|}
\hline & & voluntary & group $n=6$ & & & involuntary & group $n=9$ & & $\begin{array}{l}\text { Footpa } \\
\text { lower s }\end{array}$ & $\begin{array}{l}\text { ace: F-valu } \\
\text { stand: } p \text {-val }\end{array}$ & $\begin{array}{l}\text { ue, } \\
\text { alue }\end{array}$ \\
\hline & baseline & month 1 & month 2 & month 3 & baseline & month 1 & month 2 & month 3 & Interaction & $\begin{array}{l}\text { Between } \\
\text { groups }\end{array}$ & $\begin{array}{l}\text { Within } \\
\text { groups }\end{array}$ \\
\hline \multirow[t]{2}{*}{ self-management } & \multirow{2}{*}{$103.8 \pm 13.5$} & \multirow[b]{2}{*}{ - } & \multirow[b]{2}{*}{ - } & \multirow{2}{*}{\multicolumn{2}{|c|}{$113.7 \pm 11.0100 .6 \pm 11.5$}} & \multirow[b]{2}{*}{ 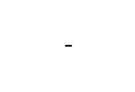 } & \multirow[b]{2}{*}{ - } & \multirow{2}{*}{$104.4 \pm 11.8$} & 2.248 & 1.099 & 11.978 \\
\hline & & & & & & & & & 0.158 & 0.314 & $0.004^{* *}$ \\
\hline \multirow[t]{2}{*}{ self-efficacy } & \multirow{2}{*}{$81.5 \pm 12.7$} & \multirow{2}{*}{ - } & \multirow{2}{*}{ - } & \multirow{2}{*}{$83.5 \pm 7.7$} & \multirow{2}{*}{$77.9 \pm 9.6$} & \multirow[b]{2}{*}{ 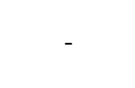 } & \multirow{2}{*}{ - } & \multirow{2}{*}{$77.3 \pm 9.0$} & 0.868 & 0.962 & 0.277 \\
\hline & & & & & & & & & 0.369 & 0.345 & 0.607 \\
\hline \multirow[t]{2}{*}{ weight } & \multirow{2}{*}{$66.4 \pm 5.7$} & \multirow{2}{*}{$66.4 \pm 5.8$} & \multirow{2}{*}{$66.4 \pm 6.0$} & \multirow{2}{*}{$66.4 \pm 6.0$} & \multirow{2}{*}{$68.7 \pm 15.8$} & \multirow{2}{*}{$68.0 \pm 15.5$} & \multirow{2}{*}{$69.0 \pm 15.3$} & \multirow{2}{*}{$67.9 \pm 15.1$} & 0.869 & 0.089 & 0.951 \\
\hline & & & & & & & & & 0.465 & 0.770 & 0.059 \\
\hline \multirow[t]{2}{*}{ BMI } & \multirow{2}{*}{$24.6 \pm 2.2$} & \multirow{2}{*}{$24.6 \pm 2.0$} & \multirow{2}{*}{$24.6 \pm 2.0$} & \multirow{2}{*}{$24.6 \pm 2.1$} & \multirow{2}{*}{$24.5 \pm 3.9$} & $242+40$ & $247+20$ & $243+20$ & 0.788 & 0.006 & 0.678 \\
\hline & & & & & & $24.3 \pm 4.0$ & $24.7 \pm 3.9$ & $24.3 \pm 3.9$ & 0.508 & 0.937 & 0.571 \\
\hline$A C$ & $91.1 \pm 6.7$ & $91.6+5.5$ & $91.8+5.3$ & $90.5+5.5$ & $90.5+9.0$ & $90.7+9.8$ & $89.8+8.9$ & $89.4+9.7$ & 1.716 & 0.072 & 4.790 \\
\hline & & & & & & & & & 0.180 & 0.793 & 0.680 \\
\hline systolic BP ${ }^{*}$ & 1 & & חר 1 & & & & $11210+18$ & & 1.795 & 2.355 & 3.777 \\
\hline & $119.7=$ & $121.0 \pm 11.0$ & $0122.0 \pm 12.0$ & $0121.0 \pm 12.4$ & $+130 .{ }_{1}$ & $1120.0 \pm 11$. & $1101.0 \pm 10.0$ & 0120.6 & 0.164 & 0.149 & 0.467 \\
\hline diastolic BP & $717 \mathrm{~d}$ & $690+50$ & $602+107$ & 2 & 36 & $747+106$ & $752+140$ & $721+112$ & 0.238 & 0.871 & 0.514 \\
\hline & $/ 1.7 \pm / .1$ & $09.9 \pm 5.8$ & $09.2 \pm 10.1$ & 70.2 & 11.1 & $74.7 \pm 10.0$ & $8.14 .5 \pm 1.3$ & $92.1 \pm 11.2$ & 0.869 & 0.368 & 0.905 \\
\hline HDL & $447+87$ & & & & 50 & & & & 0.292 & 1.214 & 1.722 \\
\hline & $44.1 \pm 0.2$ & - & - & $4 / .7 \pm 8.1$ & $50.9 \pm 11.4$ & - & - & $52.1 \pm 9.0$ & 0.599 & 0.292 & 0.214 \\
\hline LDL & $932+$ & & & 890 & 98 & & & & 1.488 & 0.907 & 0.071 \\
\hline & $93.2 \pm 20.9$ & - & - & $09.0 \pm 24.4$ & $90.4 \pm 19.0$ & - & - & $104.9 \pm 10.5$ & 0.246 & 0.360 & 0.794 \\
\hline TG & 92 & & & $1:-3$ & 0 & 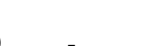 & & 12 & 0.109 & 0.343 & 0.804 \\
\hline & & & & & & & & & 0.747 & 0.569 & 0.388 \\
\hline
\end{tabular}

AC: abdominal circumference, BP: blood pressure. ${ }^{*}$ Systolic BP was curriculated by analysis of covariance, rest of the data were curriculated by repeated mearue of two-way ANOVA. ${ }^{* *} p<0.01$

Table 6. Changes in abdominal circumference of the group of continuous implementation of contents in the portfolio for 3 months.

\begin{tabular}{ccccccc}
\hline \multicolumn{2}{c}{ implementation for 3 months } & \multicolumn{2}{c}{ implementation below 2 months } & \multicolumn{3}{c}{ Footpace: F-value, lower stand: $p$-value } \\
\hline baseline & 3 months & baseline & 3 months & Interaction & Between groups & Within groups \\
\hline 92.1 & 90.8 & 90.3 & 89.5 & 0.395 & 0.102 & 5.473 \\
\pm 6.7 & \pm 6.4 & \pm 8.4 & \pm 8.8 & 0.540 & 0.755 & $0.036^{*}$ \\
\hline
\end{tabular}

${ }^{*} p<0.05$.

information was correct, meanwhile they started to follow general advice from colleagues or families regardless of whether the information was accurate or not. They were also confused because it was difficult for them to judge whether the information was suitable for them or not. On the other hands, six participants who implemented voluntarily did well from the information obtained, answering "I was glad I participated" and “it was effective”. Overall, it can be concluded that portfolio is useful for patients who are willing to get information and to implement them, and it is dangerous for patients who cannot find information by themselves. 


\subsection{Assessment of Attributes of Applicability of the Portfolio}

Portfolio implementation had less relation to age, family configuration, time-availability (work/non-work), occupation, academic background, previous health education, or economic condition. Even high internal locus of control, theoretically related to voluntarily behavioral modification [21], did not related to the implementation of portfolio against our prediction. In terms of sex, both voluntary and involuntary groups included two women; however, gender is considered to be a factor of continuation. Even they did voluntarily or not, more female continued to implement the portfolio and showed physiological effect.

Although it was not statistically significant, it is considered that high self-efficacy and high self-management were related to implementation of portfolio. Many research studies indicated that high self-efficacy related to high self-management [22] therefore, high self-efficacy might be an indicator to implement portfolio.

\subsection{Efficacy of Portfolio as a Tool for Patient Education for Patients with Ischemic Heart Diseases}

We started this portfolio as an adult education methodology which could promote self-learning, hypothesizing that adult learning increases self-efficacy, then changes in lifestyle habits, following physiological data improvement as shown in Figure 1. As we expected, selfefficacy and self-management increased in voluntary group; in contrast, no changes observed in the involuntary group. The portfolio, therefore, is considered to be effective for participants who prefer independent learning.

Interesting findings are that there was no relationship between physiological changes and voluntary/involuntary implementation of portfolio, in comparison with participants' continuity of behavior. The abdominal circumference of the participants who continued to dietary and exercise implementation for up to two months decreased. This could be interpreted that regardless of voluntary implementation, the results of physiological data relate to continuity and correct implementation of behavior. In other words, the portfolio enhances an adultlearning, but it did not have a direct connection to physiological indicators.

Considering all aspects, portfolio is applicable to patients who are willing to learn with high self-efficacy, and can be effective for secondary prevention of ischemic heart diseases, when correct and suitable information from health professionals is provided prior to start portfolio. Therefore, we conclude that portfolio is more effective if we use this as a complementary learning tool in addition to structured learning which provided proper basic knowledge and feedback to their learning by health professionals.

\subsection{Limitation of This Study and Future Implementation}

As average age of occurrence of ischemic heart disease is relatively high in Japan, Participants of younger generation was not much included in this study. In order to assess applicability and efficacy of portfolio as patient self-management education, we need to recruit more patients with younger age with various backgrounds. Physiological changes were not observed within three months. Observation period set by us could be too short to see improvement. Participants also can be expanded for patients with all kinds of chronic condition which require self-management.

\section{CONCLUSIONS}

The following points were suggested in this study.

1) Portfolio is effective as an adult education tool when it is used with prior structural health education by health professionals. However, it does not improve physiological data if they do not continuously implement behavioral modification.

2) Portfolio is dangerous if patients do not have ability to collect correct information. For these patients, health education from health professionals is required prior to conducting portfolio.

3) Effectiveness of portfolio is assumed to relate to high self-efficacy and high self-management, but it does not relate to age, living status, occupation, educational background, and health locus of control.

\section{REFERENCES}

[1] Jointly conducted with the Japanese Circulation Society in 2010 (2011) Guidelines for Secondary Prevention of Myocardial Infarction.

http://www.j-circ.or.jp/guideline/pdf/JCS2006_ishikawa_ $\underline{\text { h.pdf }}$

[2] Scottish Intercollegiate Guidelines Network (2002) Cardiac rehabilitation: A national clinical guideline. http://www.sign.ac.uk/pdf/sign57.pdf

[3] Whitman, N.I., Graham, B.A., Gleit, C.J. and Boyd, M.D. (1992) Teaching in nursing practice: A professional Model. Connecticut: Appleton \& Lange, Norwalk.

[4] Diabetes Prevention Program Research Group (2002) Reduction in the incidence of type 2 diabetes with lifestyle intervention or metformin. New England Journal of Medicine, 346, 393-403. http://dx.doi.org/10.1056/NEJMoa012512

[5] Bandura, A. (1997) Self-efficacy: The exercise of control. W. H. Freeman and Company, New York. 
[6] Howe, R. (2005) The disease manager’s handbook. Jones and Bartlett Publishers, Mississauga.

[7] Harada, K., Moriyama, M., Hyakuta, T., Nagatsuka, I. and Omori, T. (2011) The current situation of community collaboration on patient education towards prevention of recurrence of myocardial infarction. The Journal of Japan Society for Health Care Management, 12, 156-160.

[8] Matsushima, M., Honda, Y., Uchiyama, N. and Kishita, M. (2003) Actual conditions of guidance using pamphletsfor patients with myocardial infarction-Cognition and teaching methods. Nihon kangogakkaironbunshu Adult Nursing, 34, 305-307.

[9] Nishioka, K. (2003) Evaluation method of portfolio for enhancement and generalization-For new creative evaluation criteria. Tosho Bunka, Tokyo.

[10] Lewis, K.O. and Baker, R.C. (2007) The development of an electronic educational portfolio: An outline for medical education professionals. Teaching \& Learning in Medicine, 19, 139-147. http://dx.doi.org/10.1080/10401330701332219

[11] McColgan, K. and Blackwood, B. (2009) A systematic review protocol on the use of teaching portfolios for educators in further and higher education. Journal of Advanced Nursing, 65, 2500-2507. http://dx.doi.org/10.1111/j.1365-2648.2009.05189.x

[12] Kishida, A. (2008) Assistance for goal achievement in patients with type 2 diabetes who were hospitalized for the purpose of reduction in weight: Application of portfolio. Nursing Journal of Nara Prefectural Mimuro Hospital, 24, 56-58.

[13] Ishimoto, N., Shibano, T., Yoshisaka A., Takahashi, M. and Takigawa, C. (2010) Effects of portfolio aiming for self-management in chronic disease. Document of Nursing Researchat Saiseikai Shimonoseki General Hospital, 21-24.

[14] Ozoe, Y., Abe, T., Takeshita, H. and Matsumoto H. (2007) Effects of portfolio to develop ability of management of money in patients with integration dysfunction syndrome. The Japanese Psychiatric Nursing Society, 50, 380-381.

[15] Kolb, D.A. (1984) Experiential Learning experience as a source of learning and development. Prentice Hall, New Jersey.

[16] Moriyama, M., Nakano, M., Furui, Y. and Nakaya, T. (2008) A study of the efficacy of a comprehensive cardiac rehabilitation program with a focus on acquisition of self-management skills. Journal of Japan Academy of Nursing Science, 28, 17-26. http://dx.doi.org/10.5630/jans.28.4_17

[17] Ohmura, Y., Moriyama, M., Nakano, M. and Niitani, M. (2011) Development of a questionnaire to evaluate the self-management behavior of patients with ischemic heart disease. The Journal of Japanese Association of Cardiovascular Nursing, 16, 19-27.

[18] Kim, W., Shimada, H. and Sakano, Y. (1996) The relationship between self-efficacy on health behavior and stress responses in chronic disease patients. Japanese Journal of Psychosomatic Medicine, 36, 500-505.

[19] Horige Y. (1991) A Japanese version of the Health Locus of Control Scales. The Japanese Journal of Health Psychology, 4, 1-7.

[20] Wallston, K.A., Wallston, B.S. and DeVellis, R. (1978) Development of the multidimensional health locus of control (MHLC). Health Education \& Behavior, 6, 160170. http://dx.doi.org/10.1177/109019817800600107

[21] Rotter, J.B. (1966) Generalized expectancies for internal versus external control of reinforcement. Journal of Clinical Psychology, 43, 56-67.

[22] Funnell, M.M., Brown, T.L., Childs, B.P., Haas, L.B., Hosey, G.M., Jensen, B., Maryniuk, M., Peyrot, M., Piette, J.D., Reader, D., Siminerio, L.M., Weinger, K. and Weiss, M.A. (2011) National standards for diabetes selfmanagement education. Diabetes Care, 34, S89-S96. http://dx.doi.org/10.2337/dc11-S089 